\title{
Facioscapulohumeral Muscular Dystrophy: A Radiologic and Manometric Study of the Pharynx and Esophagus
}

\author{
Joerg-Patrick Stübgen ${ }^{1,2}$
}

(1) Department of Neurology, University of Pretoria, Pretoria, South Africa

(2) Department of Neurology and Neuroscience, Weill Medical College of Cornell University, 525 East 68th Street, New York, NY 10065-4897, USA

Joerg-Patrick Stübgen

Email: pstuebge@med.cornell.edu

\begin{abstract}
Facioscapulohumeral muscular dystrophy (FSHD) is not a recognized neuromuscular cause of dysphagia. However, a study of pharyngoesophageal function in FSHD has not been performed or reported. The aim of this study was to ascertain by relatively noninvasive techniques whether the dystrophic muscle disease that underlies FSHD involves the pharyngeal and/or the esophageal striated and smooth muscles. We used conventional cineradiography and intraluminal esophageal manometry on separate occasions to study pharyngeal and esophageal function in 20 patients with FSHD at various stages of disease, with or without complaints of deglutition. Age- and sexmatched control data were used for comparison of the manometric component of the study. Twelve men and eight women with FSHD were studied. The mean patient age was 38.1 years (41.9 years for controls), and the age range was 19-61 years (22-55 years for controls). The mean disease duration was 16.7 years (range $=4-39$ years).Five patients admitted to having intermittent oropharyngeal dysphagia (difficulty to initiate swallowing, cough after swallowing, sensation of food stuck in throat, or nasal regurgitation), and three patients admitted to intermittent esophageal dysphagia (difficulty swallowing both liquids and solids). Chest roentgengrams showed a hiatal hernia in four patients, but no active cardiopulmonary disease. Abnormal instrumental results were documented in eight patients: Cineradiography detected ineffectual pharyngeal contractions ( 2 patients), pharyngeal diverticula but normal pharyngeal motility (2 patients), and decreased cricopharyngeal and upper esophageal relaxation (2 patients). The mean manometric pressure of the patient group was not significantly different from the control data. However, manometry detected motility abnormalities that were not reflected in the mean data and included increased lower esophageal sphincter
\end{abstract}


resting pressure with normal or abnormal relaxation ( 2 patients) and inconsistent, highamplitude, long-duration, primary peristaltic contractions (1 patient). Patients with FSHD did not spontaneously volunteer intermittent complaints of deglutition. This study did not definitely establish that the cause of abnormal pharyngeal and cervical esophageal function was related to the dystrophic process that underlies FSHD. Any esophageal dysmotility was nonspecific and insignificant and was caused by an undetermined, probably neuropathic, process unrelated to the muscular dystrophy.

\section{Joerg-Patrick Stübgen MD}

Muscle disorders known to cause motor (neuromuscular) dysphagia include the inflammatory myopathies [1], myotonic dystrophy [2], oculopharyngeal myopathy [3], and limb girdle muscular dystrophy (LGMD) [4]. Myotonic dystrophy affects the esophageal smooth muscle with consequent weak contractions and paralysis of the esophageal body [2]. Patients with LGMD suffer nonspecific pharyngoesophageal motility disorders [4]. Patients with rigid spine syndrome (RSS) suffer dysfunction of the pharyngeal constrictors and upper esophageal sphincter [5]. Disorders of deglutition are probably underrecognized in patients with muscle disease. Patients without complaints of deglutition are usually not evaluated for a swallowing disorder. Therefore, subclinical swallowing problems may be overlooked. Alternatively, normal pharyngeal or esophageal study results are less likely to be reported.

Facioscapulohumeral muscular dystrophy (FSHD) is an autosomal dominant, slowly progressive, primary myopathy characterized by weakness predominantly of the muscles of the face and shoulder girdle [6]. FSHD is the third most common hereditary muscle disease with an estimated incidence of 1:20,000 population. The age of onset is usually between 6 and 20 years. At a molecular level FSHD is defined by the consistent association with deletions of variable size at locus q35 of chromosome $4[7,8]$. There are no genes within the deleted region. Therefore, deletions probably interfere with the expression of a gene/genes located proximal to the locus. Histopathology is consistent with a primary defect of muscle fibers, such as random variation in diameter of fibers of both types, centrally placed nuclei, necrotic and regenerating fibers, and, occasionally, collections of mononuclear cells in a perivascular distribution or in the endomysial or perimysial connective tissue [6]. A few biopsies show groups of small, angulated fibers reminiscent of denervation atrophy. FSHD supposedly spares pharyngeal muscles [9], yet there are no investigations reported that specifically studied whether this dystrophic process involves the pharyngeal or esophageal striated or smooth muscles.

None of our FSHD patients volunteered spontaneously any complaints of deglutition. However, on specific inquiry $40 \%$ of patients acknowledged complaints that hinted at possible upper alimentary tract dysfunction. Therefore, it seemed appropriate to investigate pharyngoesophageal function with relatively noninvasive conventional cineradiography and intraluminal manometry. The aim of this study was to determine whether the dystrophic process that underlies FSHD affects pharyngeal or esophageal muscles in patients with or without complaints of deglutition. 


\section{Methods}

\section{Patients}

Patients were selected based on the clinical and laboratory criteria of the International Consortium on FSHD [9]. In summary, these are (1) onset of the disease in facial or shoulder girdle muscles; sparing of the extraocular, pharyngeal, and lingual muscles, and the myocardium; (2) facial weakness in more than $50 \%$ of the affected family members; (3) autosomal dominant inheritance pattern in familial cases; and (4) evidence of myopathic electromyogram and muscle biopsy in at least one affected family member without biopsy features specific to alternate diagnoses [10].

Twenty patients of a large FSHD cohort agreed to participate in this study of the pharynx and esophagus; all patients attended the Neuromuscular Clinic (a tertiary referral center) of the University of Pretoria. Patients were selected to represent a wide spectrum of ages and durations of disease. All patients were of South African Dutch (Afrikaner) descent from the Soutpansberg region of the northern Transvaal province in South Africa.

For comparison of the manometry component of the study, we used both age- and sexmatched existing normal laboratory data and enrolled healthy control volunteers who had no complaints of deglutition or known upper alimentary tract disease. To avoid confounding statistical analysis, we selected prescreened healthy volunteers rather than a randomly selected control group to compare against the relatively small sample of patients who suffered various stages of a muscular dystrophy not known to involve pharyngoesophageal muscles. Patients were questioned about symptoms relating to the upper gastrointestinal tract, e.g., cough after swallowing, nasal regurgitation, difficulty or pain swallowing fluids or solids, and heartburn. Neither patients nor healthy volunteers used medication that interfered with the function of esophageal smooth muscle or the autonomic nervous system. All patients and volunteers gave written informed consent before participation in the study.

\section{Manual Muscle Testing}

Limb strength was assessed by the Manual Muscle Test and scored according to the British Medical Research Council (MRC) scale [11]. Quantification of global muscle strength was obtained by testing movements around the neck, shoulders, elbows, wrists, hips, knees, and ankles; 17 muscle groups on both sides were examined. For purpose of analysis the MRC scale was converted to a $1-10$-point system: $0=0 ; 2=2 ; 3-=3$; $3=4 ; 3+=5 ; 4-, 4$, and $4+=7 ; 5-=9$; and $5=10$. The average muscle score (AMS) is the numerical average of the 34 muscles tested. Out of a possible maximum score of 10 , the lower the score, the weaker the patient. 


\title{
Radiologic Evaluation
}

\author{
Chest Roentgengram
}

A full-inspiration chest X-ray was obtained for every patient to assess for active lung infection, esophageal dilatation, or hiatal hernia.

\section{Cineradiography}

Patients were studied by a solid bolus barium swallow technique and cineradiography (Marconi image intensifier). They were imaged in the erect and supine positions, and asked to swallow a one-third to one-half portion of standard marshmallow with diluted barium suspension (Baritop 100; 100-120 ml). The screening time was 1.5-4.0 min with a frame rate of 50/s. Particular attention was paid to the supine component of the study because in the erect position the effect of gravity may overcome radiographic evidence of weakness or dysfunction of the swallowing mechanism. The functions of the pharynx, M. cricopharyngeus, and esophagus were assessed according to published criteria $[12,13]$.

\section{Esophageal Manometry}

Conventional esophageal manometry was performed according to an established technique on all subjects in the supine position after a fasting period of longer than $6 \mathrm{~h}$. Intraluminal pressures were recorded on a low-compliance microcapillary infusion system (JS Biomedicals, Ventura, CA) [14]. A triple-lumen esophageal catheter (external diameter $=3 \mathrm{~mm}$ ) was passed by the nose. The three side ports were oriented radially at $120^{\circ}$ to one another and were $5 \mathrm{~cm}$ apart. The catheter was continuously perfused with distilled water at a rate of $0.6 \mathrm{ml} / \mathrm{min}$ using a pneumohydraulic infusion pump. The output was recorded on a 4-channel Synectics polygraph system. Lower esophageal sphincter (LES) pressure was measured at end-inspiration and end-expiration by a standard station pull-through technique (the catheter was withdrawn from the stomach at $0.5-\mathrm{cm}$ increments). Values were recorded as means of pressure readings of five pullthroughs. For esophageal body manometry, the catheter tip was positioned $5 \mathrm{~cm}$ above the upper border of the LES so that the distal, middle, and proximal ports were 5, 10, and $15 \mathrm{~cm}$ from this sphincter, respectively.

Amplitude of contractions (in $\mathrm{mmHg}$ ) was measured from the esophageal baseline pressure to the peak of the complex. Contraction duration (in seconds) was measured from the intersection of lines for the mean resting intraesophageal pressure and the upstroke of the complex to its return to the mean resting pressure.

Mean values were determined from ten wet swallows ( $5 \mathrm{ml}$ water) at 30-s intervals. Upper esophageal sphincter (UES) pressure was measured by slight modification of the rapid pull-through technique, with breath held in mid-inspiration and the patient's neck in a comfortable extension $[15,16]$. Sphincter pressure was recorded in $\mathrm{mmHg}$ above esophageal baseline pressure. The oral end of the UES was defined as $10 \mathrm{mmHg}$ above baseline. Controversies surround the interpretation of UES pressure measurements 
obtained with a triple-lumen catheter [17, 18]. Because the same technique was used by the same investigator on all subjects and the mean of 15 readings ( 5 pull-throughs for 3 orifices) per patient was used for analysis, this study was regarded as acceptable for evaluating interpatient and intergroup differences. Results of pressure records for any subject were abnormal if values fell outside the group mean plus 2 SD (standard deviation) and were not adjusted for age.

\section{Statistical Analysis}

The Pearson correlation coefficient was used to (1) determine the relation between patient age and disease duration, and AMS, and (2) to compare the means of the esophageal manometry results in the patient versus control group. The statistical significance of data was established at $p<0.05$. This protocol was used also in studies of patients with limb girdle muscular dystrophy and rigid spine syndrome $[4,5]$.

\section{Results}

\section{Patients}

The mean age of the 20 patients (12 males, 8 females) was 38.1 years (range $=19$ 61 years) (Table 1). The mean age for volunteer controls was 41.9 years (range $=22$ 55 years). The mean duration of the disease was 16.7 years (range $=4-39$ years). The mean AMS was 7.7 of 10 (range $=6.2-9.1)$. There was a statistically highly significant correlation between patient age and disease duration $(p<0.001)$. There was an inversely significant correlation between patient age and the AMS, and between disease duration and the AMS (both $p<0.001$ ), as expected for a progressive muscle dystrophic disease.

Table 1 Patient information

\begin{tabular}{|l|l|l|l|l|l|l|l|l|}
\hline Patient & $\begin{array}{l}\text { Age } \\
\text { (years) }\end{array}$ & Sex & $\begin{array}{l}\text { Disease } \\
\text { duration } \\
\text { (years) }\end{array}$ & $\begin{array}{l}\text { AMS } \\
(/ 10)\end{array}$ & Dysphagia & CXR & Radiology & Manometry \\
\hline 1 & 19 & M & 5 & 8.5 & & & & \\
\hline 2 & 22 & M & 4 & 8.7 & & + & & \\
\hline 3 & 26 & F & 7 & 9.1 & + & + & + & \\
\hline 4 & 27 & M & 5 & 8.3 & & & & + \\
\hline 5 & 29 & F & 10 & 7.9 & & + & & \\
\hline 6 & 29 & F & 7 & 7.7 & + & & + & \\
\hline 7 & 31 & M & 6 & 8.4 & & & & \\
\hline 8 & 34 & M & 14 & 7.1 & & + & & \\
\hline 9 & 35 & M & 9 & 8.6 & & & & \\
\hline 10 & 38 & F & 17 & 8.3 & + & & + & \\
\hline
\end{tabular}




\begin{tabular}{|l|l|l|l|l|l|l|l|l|}
\hline Patient & $\begin{array}{l}\text { Age } \\
\text { (years) }\end{array}$ & Sex & $\begin{array}{l}\text { Disease } \\
\text { duration } \\
\text { (years) }\end{array}$ & $\begin{array}{l}\text { AMS } \\
(/ 10)\end{array}$ & Dysphagia & CXR & Radiology & Manometry \\
\hline 11 & 39 & M & 20 & 7.7 & + & & & + \\
\hline 12 & 39 & M & 14 & 7.5 & & & & \\
\hline 13 & 42 & F & 25 & 6.9 & + & + & + & \\
\hline 14 & 43 & F & 18 & 7.5 & & & & \\
\hline 15 & 45 & M & 22 & 8.1 & & & & \\
\hline 16 & 45 & F & 26 & 7.0 & + & & & \\
\hline 17 & 47 & M & 20 & 7.4 & & + & + & \\
\hline 18 & 53 & M & 34 & 6.7 & + & & & + \\
\hline 19 & 57 & M & 31 & 7.1 & & & & \\
\hline 20 & 61 & F & 39 & 6.2 & + & + & + & \\
\hline
\end{tabular}

\section{Dysphagia}

Eight patients ( 6 women, 2 men) acknowledged swallowing difficulty. Five patients admitted to apparent intermittent oropharyngeal (pre-esophageal) dysphagia with complaints of nasal regurgitation of liquids (patient 3), coughing/choking on swallowing fluids and/or solids (patients 6 and 20), sensation of food "sticking" in throat (patients 3 and 16), or difficulty initiating swallowing (patient 10). Three patients admitted to apparent intermittent esophageal dysphagia as they complained of difficulty swallowing fluids and solids "on the way down" (patients 11, 13, and 18). No patient gave a history of aspiration pneumonia. No patient suffered a nasal speech; any dysarthria was due to perioral facial weakness of FSHD.

\section{Radiologic Evaluation}

\section{Chest Roentgengrams}

No patient suffered active cardiopulmonary disease. Patients 2 and 17 suffered thoracic scoliosis and kyphoscoliosis, respectively. Patients 3, 8, and 13 suffered sliding hiatal hernia, and in patient 20 a paraesophageal hiatal hernia was detected. Patient 5 suffered an elevated right hemidiaphragm (possibly related to the muscle dystrophy).

\section{Cineradiography}

In 14 patients the solid barium and cineradiographic studies were normal, including patient 16 who complained of food getting stuck in her throat. In patients 3 and 10 the study demonstrated repeated, ineffectual contractions of the pharyngeal muscles, with slow movement of barium through the hypopharynx with a relaxed UES. In patients 6 
and 17 we detected small posterior paramedian pharyngeal diverticula, yet normal movement of barium through the pharynx and UES. Patient 13 showed slow passage of barium through the hypopharynx due to incomplete cricopharyngeal muscle relaxation. Patient 20 showed slow relaxation of the cervical esophagus preceding primary peristaltic contraction with subsequent proximal escape of barium through the UES into the hypopharynx.

\section{Esophageal Manometry}

UES, esophageal body, and LES pressures for both FSHD and control groups (expressed as group means $\pm 1 \mathrm{SD}$ ) are summarized in Table 2. Group means were not statistically different when patient and control data were compared. Manometry established normal esophageal motility in 17 patients, but three patients showed abnormalities that were not reflected in the group data.

Table 2 Results of esophageal manometry

\begin{tabular}{|c|c|c|}
\hline & Patients & Controls \\
\hline \multicolumn{3}{|c|}{ Esophageal body [mean (SD) amplitude (mmHg) } \\
\hline Proximal (1/3) & $56(23)$ & $60(20)$ \\
\hline Mid (2/3) & $65(24)$ & $61(27)$ \\
\hline Distal (3/3) & $102(27)$ & $97(20)$ \\
\hline \multicolumn{3}{|c|}{ Esophageal body [mean (SD) duration (s)] } \\
\hline Proximal (1/3) & $2.8(1.0)$ & $3.1(1.5)$ \\
\hline Mid (2/3) & $3.5(1.3)$ & $3.3(1.7)$ \\
\hline Distal (3/3) & $4.0(1.1)$ & $3.6(0.8)$ \\
\hline \multicolumn{3}{|c|}{ Lower esophageal sphincter pressure $(\mathrm{mmHg})$} \\
\hline End-expiratory & $15.4(7.2)$ & $16.1(5.9)$ \\
\hline End-inspiratory & $48.1(11.7)$ & $45.3(9.5)$ \\
\hline \multicolumn{3}{|c|}{ Upper esophageal sphincter pressure $(\mathrm{mmHg})$} \\
\hline Peak & $70.1(14.0)$ & $72.7(11.6)$ \\
\hline
\end{tabular}

Results expressed as means ( $\pm 1 \mathrm{SD}$ )

The difference of all mean test results of patients and controls did not reach statistical significance

In patient 4 (without dysphagia) we determined an increased LES resting pressure but normal relaxation with deglutition and normal thoracic esophageal peristalsis ("the hypertensive" LES [19]). In patient 11 we detected an inconsistent (3/10 swallows) increase in the amplitude of the primary peristaltic esophageal contractions, and an inconsistent (4/10 swallows) increase in the prolongation of the duration of esophageal contractions, and with normal peristaltic progression. LES resting pressure and relaxation 
were normal. The results did not fulfill the criteria for "nutcracker" esophagus (mean pressure of swallow responses $>180 \mathrm{mmHg}$; mean duration of swallow responses $>6 \mathrm{~s}$ ) [20]. Manometry in patient 18 showed elevated LES resting pressure and decreased relaxation with deglutition and normal thoracic esophageal peristalsis.

\section{Discussion}

This study reports on the only cineradiologic and manometric evaluation of pharyngoesophageal function in patients with FSHD. FSHD is not listed as a cause of oropharyngeal or esophageal dysphagia, yet $40 \%$ of our patients admitted to swallowing difficulty. Therefore, we undertook this study to ascertain whether the dystrophic process involves the striated or smooth muscle of the pharynx and esophagus.

The facioscapulohumeral syndrome comprises several disorders that can cause diagnostic confusion [6]. Until the recent interest in genetic linkage studies, FSHD received little attention because of its benign prognosis and the perception that it represented a syndrome rather than a distinct myopathy [8]. Patients with characteristic facial and shoulder weakness and an autosomal dominant family history invariably suffer the dystrophic form of this syndrome [6]. For this study, patients were carefully selected based on the criteria of the International Consortium on FSHD [9]. All patients were South African Dutch (Afrikaner) descendents from the Soutpansberg area of the northern Transvaal province, thus they were a homogeneous group. There was a correlation between both increasing patient age and disease duration and progressive limb weakness, as expected for a progressive dystrophic process The relatively well-maintained strength in even the oldest patients was evidence of the benign course of this dystrophy. However, such an evaluation of limb strength does not take into consideration an assessment of facial and pharyngoesophageal muscles. None of our patients volunteered spontaneously any complaints of deglutition. This could be a reason why this type of study was not previously undertaken or reported on patients with FSHD. However, on specific inquiry $40 \%$ of patients admitted to complaints that hinted at possible upper alimentary tract dysfunction. Also, we reported on the inexact correlation between any swallowing complaints and instrumental findings in patients with limb girdle muscular dystrophy and rigid spine syndrome $[4,5]$. Therefore, it seemed appropriate to study by relatively noninvasive techniques even asymptomatic FSHD patients to assess for a possible deglutition disorder.

As in our previous studies on limb girdle muscular dystrophy and rigid spine syndrome $[4,5]$, in this patient group we also observed an imperfect correlation between complaints of apparent oropharyngeal or esophageal dysphagia and study results and an inexact correlation between study results. More women than men acknowledged swallowing difficulty, though instrumental results did not bear out any numerical difference between the sexes. However, the study format and patient sample size were not designed to address a potential gender influence on any upper alimentary tract dysfunction. There also was no obvious correlation between patient clinical parameters and evidence of 
impaired deglutition, so that any pharyngoesophageal skeletal and smooth muscle dysfunction cannot be regarded as a consequence of the natural history of this dystrophy.

Five patients complained of oropharyngeal dysphagia. Cineradiography demonstrated in two patients ineffectual contractions of the pharyngeal striated muscle with slow bolus movement through the hypopharynx despite a relaxed UES. We speculated whether this hypomotility was due to weakened pharyngeal constrictors affected by the dystrophic process. However, there was no opportunity to obtain pathologic proof of a definite cause-effect relationship.

Cineradiography detected a pharyngeal (Zenker's) diverticulum without demonstrated abnormality of pharyngeal motility in two patients with and without oropharyngeal dysphagia. Combined observations suggest that this posterior outpouching of the mucosa and submucosa through the relatively weak posterior pharyngeal wall (Killian's dehiscence) results from increased hypopharyngeal intraluminal pressure due to a poorly compliant but normally relaxing UES that cannot fully distend during the process of sphincter opening [21-23]. It is possible that we were unable to document any lower pharyngeal dyssynergia because a cineradiographic study represents only a "snapshot" of the patient's overall swallowing ability and cannot be relied on to be representative [24]. Although we lack pathologic proof, we speculate that the dystrophic process of FSHD contributed to the evolution of the pouches by weakening the pharyngeal wall or decreasing cricopharyngeal compliance through muscle fiber degeneration and fibroadipose tissue replacement [22]. Further support for such an association was based on the detection of diverticula in our patients at a relatively young age (median age of presentation reported in the eighth decade [23]), but low patient numbers did not allow comment on whether these pouches occurred more often in patients with FSHD compared to the general population.

Cineradiography demonstrated in two patients (with apparent oropharyngeal and esophageal dysphagia) evidence of decreased cricopharyngeal and cervical esophageal relaxation, respectively. Chest roentgengrams showed that these patients suffered paraesophageal and sliding hiatal hernias. We believed that the upper alimentary tract dysmotility was reflux-induced [25] and unrelated to the muscle disease of FSHD. Published reports on biopsy specimens of the cricopharyngeal muscle in patients with gastroesophageal reflux-induced oropharyngeal dysphagia showed mild-to-severe fibrosis and ultrastructural abnormalities on electron microscopy, such as numerous and aberrant mitochondria, increased glycogen, lipid inclusions, phagolyzosomes, and nemaline rods $[26,27]$. It has been postulated that these pathologic changes are a secondary response to reflux-induced injury.

Manometry detected minor abnormalities of esophageal contractility or LES relaxation in three patients with FSHD. These results were best categorized as nonspecific esophageal motility disorders (including "the hypertensive" LES) and were of uncertain significance. Findings overlapped with, but did not meet the full criteria of, distinct and wellcharacterized disorders such as achalasia, diffuse esophageal spasm, and the "nutcracker" esophagus $[14,19,20,23,25]$. These nonspecific disorders of motility can evolve into 
other and more specific esophageal motor disorders so that the boundaries remain rather plastic [25]. Thus, we suspected that the patient with increased LES tone and decreased relaxation on deglutition was at risk for developing achalasia, because dysfunction of the LES seems factorial in the genesis of aperistalsis of the esophageal body [25, 28]; sometimes these abnormalities are transient [29] so that our patients will require followup studies.

It is presumed that primary motor disorders of the esophagus are usually secondary to a separate disease process anatomically remote from those producing oropharyngeal dysphagia [25]. Based on results of this study, it was questionable whether the FSHD dystrophic process affected the pharyngeal striated muscle, and there was no evidence that this myopathy involved the esophageal smooth muscle. The motility abnormalities detected in this series have been reported in non-neuromuscular patients with upper alimentary complaints and, less commonly, in asymptomatic, healthy volunteers [14]. Furthermore, histologic and immunohistochemical studies indicated that a primary degenerative neuropathic cause usually underlies motility disorders of the esophagus [ 30 34]. Esophageal smooth muscle histology was reported normal or showed changes consistent with denervation atrophy $[30,35]$. Although we had no access to such tissue in our patients, such findings are incompatible with a primary muscle disease such as FSHD that is not known to involve the central or peripheral nervous systems.

In summary, patients with FSHD did not spontaneously volunteer complaints of deglutition. There was no clear evidence that the myopathic process that underlies FSHD involved pharyngeal and upper esophageal striated muscle. Minor, and nonspecific, primary esophageal dysmotility was presumably caused by an undetermined neuropathic process distinct from FSHD.

\section{References}

1. Engel AG, Hohlfeld R, Banker BQ. The polymyositis, dermatomyositis syndromes. In: Engel AG, Franzini-Armstrong C (eds.), Myology, 2nd ed. New York: McGrawHill, 1994, pp 1335-1383.

2. Harper PS. Myotonic Dystrophy. Philadelphia: WB Saunders, 1979

3. Tome FMS, Fardeau M. Ocular myopathies. In: Engel AG, Franzini-Armstrong C (eds.), Myology, 2nd ed. New York: McGraw-Hill, 1994, pp 1233-1245.

4. Stübgen J-P. Limb girdle muscular dystrophy: A radiologic and manometric study of the pharynx and esophagus. Dysphagia 1996;11:25-29.

5. Stübgen J-P. Rigid spine syndrome: A radiologic and manometric study of the 
pharynx and esophagus. Dysphagia 2007.

6. Munsat TL. Facioscapulohumeral disease and the scapuloperoneal syndrome. In: Engel AG, Franzini-Armstrong C (eds.), Myology, 2nd ed. New York: McGraw-Hill, 1994, pp 1220-1232.

7. Tawil R, Griggs RC. Facioscapulohumeral muscular dystrophy. In: Rosenberg RN, Prusiner SB, DiMauro S, Barchi RL (eds.), The molecular and genetic basis of neurological disease. Boston: Butterworth-Heinemann, 1997, pp 931-938.

8. Tawil R, Figlewicz DA, Griggs RC, Weiffenbach B. FSH Consortium, Facioscapulohumeral dystrophy: A distinct regional myopathy with a novel molecular pathogenesis. Ann Neurol 1998;43:279-282.

9. Padberg GW, Lamont PW, Koch M, Fardeau M. The diagnostic criteria for facioscapulohumeral dystrophy. Neuromusc Disord 1991;1:231-234.

10. Stübgen J-P. Facioscapulohumeral muscular dystrophy: A quantitative electromyographic study. Electromyogr Clin Neurophysiol 2007;47:175-182.

11. Mendell JR, Florence J. Manual muscle testing. Muscle Nerve 1990;13 Suppl:16-20.

12. Dodds WJ, Radiology (of the esophagus and esophagogastric region). In: Margulis AR, Burhenne HJ (eds.), Alimentary Tract Radiology. St. Louis: C.V. Mosby, 1983, pp 529-603.

13. Seaman WB, Radiology (of the pharynx). In: Margulis AR, Burhenne HJ (eds.), Alimentary Tract Radiology. St. Louis: C.V. Mosby, 1983, pp 491-518.

14. Richter JE, Wu WC, Johns DN, Blackwell JN, Nelson JL, Castell JA, Castell DO. Esophageal manometry in 95 healthy volunteers. Variability of pressure with age and frequency of "abnormal” contractions. Dig Dis Sci 1987;32:583-592.

15. Dodds WJ, Hogan WJ, Stef JJ, Miller WN, Lydon SB, Andorfer RC. A rapid pullthrough technique for measuring lower oesophageal sphincter pressure.

Gastroenterology 1975;68:437-443.

16. Welch RW, Luckman K, Ricks PM, Drake ST. Manometry of the normal upper oesophageal sphincter and its alteration in laryngectomy. J Clin Invest 1979;63:10361041. 
17. Winans CS. The pharyngoesophageal closure mechanism: a manometric study. Gastroenterology 1972;63:768-777.

18. Castell JA, Castell DO. Modern solid state computerized manometry of the pharyngoesophageal segment. Dysphagia 1993;8:270-275.

19. Berger K, McCallum RW. The hypertensive lower esophageal sphincter. Gastroenterology 1981;80:1109-1114.

20. Bremmer CG, DeMeester TR, Huprich JE, Bremmer RM. Esophageal disease and testing. New York: Taylor \& Francis, 2005, pp 53-69.

21. Cook IJ, Gabb M, Panagopuolos V. Pharyngeal (Zenker's) diverticulum is a disorder of upper esophageal sphincter opening. Gastroenterology 1992;103:1229-1235.

22. Cook IJ, Blumbergs P, Cash K. Structural abnormalities of the cricopharyngeal muscle in patients with pharyngeal (Zenker's) diverticulum. J Gastroenterol Hepatol 1992;7:556-562.

23. Cook IJ. Disorders causing oropharyngeal dysphagia. In: Castell DO, Richter JE (eds.), The esophagus. Philadelphia: Lippencott, Williams \& Wilkens, 2004, pp 196220 .

24. Wiles CM. Neurogenic dysphagia. J Neurol Neurosurg Psychiatry 1991;54:10371039.

25. Nowak TV. Motility disorders of the esophagus. In: Anuras S (eds.), Motility disorders of the gastrointestinal tract. New York: Raven Press, 1992, pp 345-368.

26. Cruse JP, Edwards DAW, Smith JF, Wyllie JH. The pathology of cricopharyngeal dysphagia. Histopathology 1979;3:223-232.

27. Henderson RD, Hanna WM, Henderson RF, Marryatt G. Myotomy for reflux-induced cricopharyngeal dysphagia. Five year review. J Thorac Cardiovasc Surg 1989;98:428-433.

28. Richter JE. Achalasia. In: Castell DO, Richter JE (eds.), The esophagus. Philadelphia: Lippencott, Willaiams \& Wilkens, 2004, pp 221-256.

29. Demeester TR, Dunnington GL. Esophageal anatomy and physiology. In: Greenfield LJ, Mulholland MW, Oldham KT, Zelenock GB (eds.), Surgery: Scientific Principles 
and Practice. Philadelphia: Lippencott, 1993, pp 593-621.

30. Paterson WG. Etiology and pathogenesis of achalasia. Gastrointest Endosc Clin North Am 2001;11:249-265.

31. Wattchow DA, Costa M. Distribution of peptide-containing nerve fibers in achalasia of the esophagus. J Gastroenterol Hepatol 1996;11:478-482.

32. DeGiorgio R, Di Simone MP, Stanghellini V. Esophageal and gastric nitric oxide synthesizing innervation in primary achalasia. Am J Gastroenterol 1999;94:23572362 .

33. Mellow M. Symptomatic diffuse esophageal spasm. Manometric follow-up and response to cholinergic stimulation and cholinesterase inhibition. Gastroenterology 1977;73:237-240.

34. Cole MJ, Paterson WG, Beck IT, DaCosta LR. The effect of acid and betanechol stimulation in patients with symptomatic hypertensive peristaltic (nutcracker) esophagus. Evidence that this disorder may be a precursor of diffuse esophageal spasm. J Clin Gastroenterol 1986;8:223-229.

35. Friesen DL, Henderson RD, Hanna W. Ultrastructure of the esophageal muscle in achalasia and diffuse esophageal spasm. Am J Clin Pathol 1983;79:319-325. 